\title{
Historia y situación actual de la enseñanza de español en la R. P. China
}

\author{
ALEJANDRO VÁZQUEZ TORRONTERAS \\ Shenzhen University \\ torronteras7@gmail.com
}

ANTONIO ÁLVAREZ BAZ

Universidad de Granada

antxon@ugr.es

MA LIYA

Shenzhen University

maliya@szu.edu.cn

\section{Resumen}

El propósito del presente artículo es exponer la historia y la situación actual de la enseñanza de español en la R. P. China. Para ello, presentamos información detallada sobre el origen de la presencia de la lengua española en este país, así como su posterior desarrollo hasta llegar al boom que está experimentando en la actualidad. Asimismo, explicamos los diferentes contextos en los que se enseña la lengua española en este país. Nos centramos en la enseñanza superior, por lo que explicamos en detalle la realidad del grado universitario en Filología Hispánica en la R.P. China y las peculiaridades que lo hacen diferente del mismo grado en otros países. En definitiva, este artículo tiene como propósito principal presentar el pasado y presente de la enseñanza de español en la R. P. China, y puede servir como indicativo de lo que nos depara el futuro en este ámbito. Un futuro que, de acuerdo con los datos que se presentan en este artículo, nos hace prever un aumento progresivo del protagonismo de la enseñanza de español en el gigante asiático.

\section{Palabras clave}

Español; enseñanza; cultura; R.P. China; universidad. 


\title{
History and current situation of the teaching of Spanish in the P. R. China
}

\begin{abstract}
The purpose of this article is to present the history and the current outlook of Spanish teaching in the P. R. China. To that end, we present detailed information about the origin of the Spanish language in this country, as well as its subsequent development until reaching the boom it is currently experiencing. In addition, we explain the different contexts in which the language of Cervantes is taught in this country. Likewise, we focus on higher education, so we explain in detail the reality of the university degree in Hispanic Philology in the P. R. China and the peculiarities that make it different from the same degree in other countries. To sum up, the main purpose of this article is to present the past and present of teaching Spanish in the P. R. China and can serve as an indication of what the future holds for us in this area. A future that, regarding to the information presented in this article, brings a progressive increase in the role of Spanish teaching in the Asian giant.
\end{abstract}

\section{Keywords}

Spanish; teaching; culture: P.R. China; university.

Recibido el 08/07/2020

Aceptado el 28/10/2020 


\section{Introducción}

La enseñanza de español en la R.P. China está experimentando un crecimiento exponencial en el siglo XXI; estamos siendo protagonistas de un auge del español en este país en los últimos años. Cada año nos encontramos con la apertura de nuevos departamentos de lengua española en universidades chinas y con la llegada de nuevos estudiantes chinos a centros de enseñanza en España. La situación en el resto de contextos de enseñanza es similar; un reciente ejemplo es la inclusión del español en el currículo de lenguas elegibles para la prueba de acceso a la Universidad (el gaokao, 高考 $)^{1}$, de acuerdo con los nuevos estándares que siguen los institutos de enseñanza secundaria en los centros de todo el país. Este plan fue publicado en un documento ofrecido por el Ministerio de Educación de la R.P. China en 2018², producto de un trabajo que se inició en 2013 y que duró cinco años. Asimismo, se hace notable el crecimiento por el interés en aprender en español en contextos de enseñanza no reglada, como academias privadas o el Instituto Cervantes. Para poder formarnos una opinión lo más real posible sobre el aumento de estudiantes en las universidades chinas, es suficiente con afirmar que desde el año 2000 y hasta el año 2013 el número pasó de ser de 500 a 15000 (Lu, 2015). Es decir, hubo un crecimiento de un 3.000 \%, y este aumento continúa vigente en la actualidad.

En este artículo pretendemos exponer los comienzos del español en la R.P. China, mostrar el desarrollo experimentado a lo largo de estos últimos años y concluir dando el máximo detalle de los programas del Grado en Filología Hispánica en las universidades de la R.P. China, por ser el contexto que ocupa el mayor porcentaje de alumnos. Para ello, vamos a comenzar con una breve historia de la enseñanza de español como lengua extranjera (ELE) en este país; en este primer apartado haremos un resumen desde los orígenes hasta nuestros días. En el siguiente apartado vamos a enumerar los diferentes ámbitos de enseñanza de ELE y presentaremos algunas peculiaridades de cada uno de ellos. Para concluir, analizaremos de forma exhaustiva las particularidades y los planes de estudio del Grado en Filología Hispánica.

\section{Orígenes e historia del español en la R.P. China}

Para hallar los primeros contactos entre la lengua española y el gigante asiático tenemos que remontarnos hasta el siglo XVI, concretamente a la llegada de misioneros que intentaban entrar en China en misión evangelizadora (Fisac, 2000: en línea). Durante este siglo, los misioneros que se encontraban en Filipinas esperaban impacientes el momento de entrar en contacto con China y establecer relaciones, pero

\footnotetext{
1 Prueba de acceso para las universidades chinas similar a la selectividad española.

2 Hemos consultado esta información en el documento original, publicado en chino, titulado 普通高中西班牙语 课程标准, que en español podría traducirse como Estándar Curricular para la Enseñanza del Español en Escuelas Secundarias. Este documento fue publicado en 2018 por la editorial china 人民教育出版社 (People's Education Press).
} 
en ese momento la entrada extranjera a China se condenaba con la pena de muerte. Los evangelizadores, pese a ello, estaban dispuestos a entrar, aunque tuvieran que arriesgar su vida y hacerse pasar por esclavos, ya que esta era la única manera mediante la cual un extranjero podía acceder a China. Finalmente, los primeros misioneros consiguieron entrar a finales del siglo XVI. Este fue el caso del jesuita Diego de Pantoja (1571 - 1618), que llegó en el año 1597, y, pese a que fue expulsado en 1617, llegó a entrar en la corte de aquel entonces, difundió su doctrina en chino y fundó la comunidad jesuíta en Pekín (Zhang, 2009).

Con la disolución del Imperio Español desaparecieron también las relaciones entre China y España, que desde ese momento entraron en un largo periodo de silencio. No obstante, contamos con documentos que nos indican que este vacío no fue total. Este es el caso del Dictionarium Hispano-Sinicum, del siglo XVII, en el que aparecen registrados vocablos en español, en chino y en un dialecto local de la China de aquel entonces. Este diccionario fue de utilidad para los comerciantes sangleyes, considerados los primeros emigrantes chinos, y para los misioneros que residían en Filipinas (Gil, 2019: en línea).

Después de estos primeros contactos, se entraría en una larga etapa de silencio que duraría hasta la primera mitad del siglo XX, momento en el que la presencia del español era si cabe muy reducida. No obstante, comienzan a publicarse algunos diccionarios bilingües y diversas obras literarias españolas logran ser traducidas al chino (Santos Rovira, 2011: 14). Hasta bien entrado el siglo XX no hallamos obras dedicadas a la lengua española, y estas fueron escritas por chinos; la primera obra de la que se tiene noticia es el Diccionario Español-Chino Enciclopédico (1917), de Tan Yihao, que daba cabida a más de 30000 voces. Por parte de España, fueron los misioneros religiosos los que se dedicaron a la publicación de obras filológicas, con un doble objetivo: difusión de la lengua española y evangelización.

En 1949 se fundó la República Popular China, y en aquel momento la lengua extranjera predominante era el ruso $^{3}$, que fue obligatorio hasta los años 70 . Cuatro años más tarde del nacimiento de la República Popular, se implantaron los estudios de filología hispánica. Los primeros materiales y los primeros profesores de español fueron rusos y, como no podía ser menos, la metodología también se importó de Rusia (Unión Soviética), debido, en principio, a la carencia de recursos y al bloqueo que sufría China de parte del mundo occidental (Dong, 2009: 1).

Respecto de las universidades, la enseñanza de español comenzó en 1952 en el Instituto de Lenguas Extranjeras de Pekín (Zheng et al., 2014: 575). Este inicio fue anecdótico. Nos cuenta Huang Wei (2014: 2) que con motivo de la celebración en el Instituto de Lenguas Extranjeras de Pekín en 1952 del congreso Peace Conference of the Asian and Pacific Regions, al que asistieron delegaciones de Perú, Chile, Ecuador, México y Colombia, el gobierno chino se dio cuenta de la necesidad de la formación de traductores e intérpretes de español, por lo que se empezaron a impartir los primeros cursos de ELE en esta institución. Un año después, en 1953, se inauguró en esta universidad la primera Licenciatura en Filología Hispánica, formándose así los primeros licenciados chinos, pioneros en este campo. Un año más tarde, la Universidad de

${ }^{3}$ China recibía en aquellos tiempos una gran influencia de la Unión Soviética. 
Economía y Comercio Exterior de Pekín implantó en sus aulas cursos de lengua española y a ella le siguieron la Universidad de Estudios Internacionales de Shanghái y la Universidad de Pekín (Fisac, 2000: en línea).

Por otra parte, a pesar de este prometedor comienzo, en 1956 solo había once profesores de español, y desde 1953 hasta 1956 únicamente se graduaron cuarenta y un alumnos de español (Marco, C. y Marco, J, 2010: 4). El principal motivo de que en estos años se diera esta situación lo encontramos en el dominio del ruso como primera lengua extranjera en China en los años cincuenta, fruto de la estrecha relación entre China y la URSS comentada anteriormente, convirtiéndose el ruso así en lengua obligatoria en los centros educativos. Asimismo, las relaciones diplomáticas entre China y otros países occidentales todavía eran escasas, por lo que la enseñanza de otras lenguas extranjeras era casi inexistente, exceptuando casos como el de la Universidad de Lenguas Extranjeras de Pekín ya mencionado.

A partir de la década de los sesenta la situación en el ámbito de la enseñanza de ELE empezó a mejorar; en 1960 se abrieron nuevos departamentos de español en universidades como la Universidad de Pekín o la Universidad de Estudios Internacionales de Shanghái, las cuales hoy en día siguen siendo un referente en China en este campo. Por otro lado, en 1962 fue publicado el primer manual para el aprendizaje de lengua española, titulado Español. Este manual, realizado por el Departamento de Español de la Universidad de Lenguas Extranjeras de Pekín, supuso un primer y gran paso para la sistematización de la enseñanza del español en China (Dong, 2009: 59). Al mismo tiempo, en estos años se incrementaron las relaciones con los países hispanoamericanos, lo que provocó un aumento del interés por el estudio de la lengua española, incrementando así el número de estudiantes de español en China.

Con la Revolución Cultural China (1966 - 1976) llegó la ruptura de las buenas relaciones con Rusia y comenzó un periodo en el que todo lo extranjero se consideraba sospechoso o contrario al régimen. En este periodo no se produjo avance alguno en el ámbito de la enseñanza de lenguas extranjeras. El final de la Revolución Cultural y, sobre todo, tras la llegada al poder de Deng Xiaoping 4 en 1978, provocó que se volviera a instaurar la enseñanza de lenguas extranjeras en las universidades, y ello propició la recuperación de la enseñanza de lenguas extranjeras en China.

Desde el año 1997 el auge económico de China viene acelerando el desarrollo del español; en comparación con la cifra de 1979, y pese al cierre de departamentos que se produjo en los ochenta, el número de estudiantes universitarios matriculados se acrecentó hasta un 332 \% (Lin, 2015: 422). Hasta el año 1999 había en China un total de 12 universidades que ofrecían los estudios de español como especialidad, cuyo número de estudiantes era de unos 500. Por ejemplo, en el primer Examen de Español como Especialidad (EEE) de nivel $4\left(\mathrm{EEE4}^{5}\right.$ ) que se realizó en China en el año 1999 hubo 123 estudiantes matriculados (Zheng, 2011: 575).

\footnotetext{
4 (1904 - 1997), máximo líder de la República Popular de China desde 1978 hasta su muerte.

5 El Examen de Español como Especialidad de nivel 4 es un examen dirigido a estudiantes universitarios de segundo curso del Grado en Filología Hispánica en la R.P. China. Este examen también se realiza a los estudiantes de cursos superiores que aún no han superado la prueba.
} 
Si observamos detenidamente el siguiente gráfico sobre la evolución del examen EEE4, elaborado a partir de los datos proporcionados por el comité organizador, vemos claramente el espectacular incremento de estudiantes universitarios de español en la R.P. China:

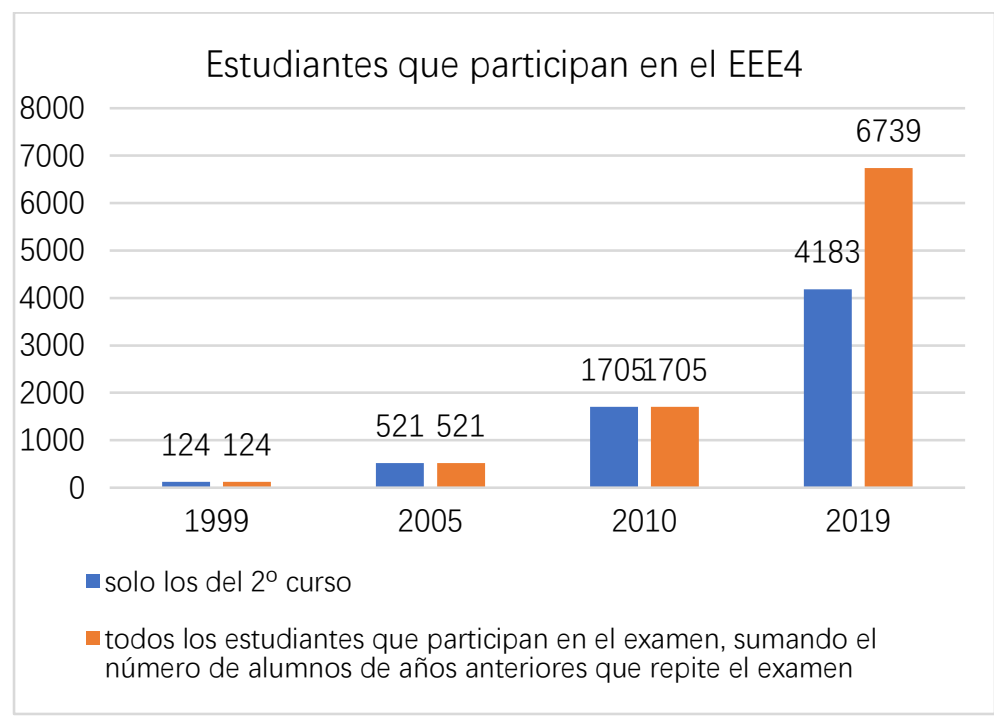

Fuente: datos proporcionados por el comité de organización del EEE4 a los profesores universitarios chinos

Del 2000 al 2010 se abrieron 50 nuevos departamentos de español en China, es decir, se multiplicó por cuatro el número de departamentos existentes. Así, en 2010 el número de alumnos matriculados en el EEE4 fue de 1700, 14 veces la cifra de 1999.

González Puy (2006: 134), directora del Instituto Cervantes de Pekín, afirmaba en el año 2006 la incapacidad por aquel entonces de las universidades de atender la demanda de estudiantes que querían acceder al Grado en Filología Hispánica.

En el siguiente gráfico podemos apreciar el gran ritmo de crecimiento en el número de alumnos de español matriculados en universidades de la R.P. China entre los años 2000 y 2006.

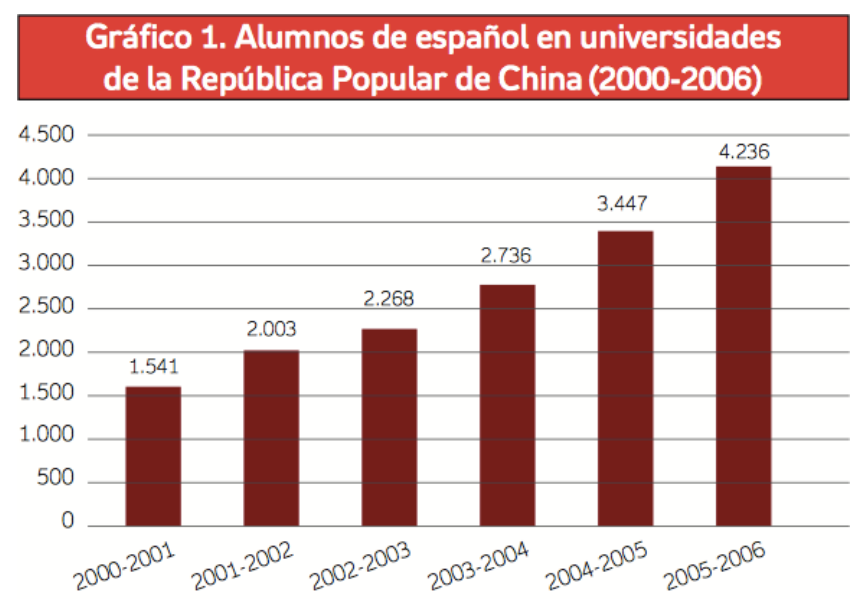

Fuente: González Puy (2006: 137) 
A la información proporcionada en el gráfico precedente podemos añadir datos de años posteriores. En 2012 hallamos más de 10000 estudiantes, y en 2017 más de 15000 (Lu, 2018: 408-409). De acuerdo con los datos obtenidos en el estudio de Lu, hemos podido elaborar el siguiente gráfico, que complementa al gráfico expuesto anteriormente:

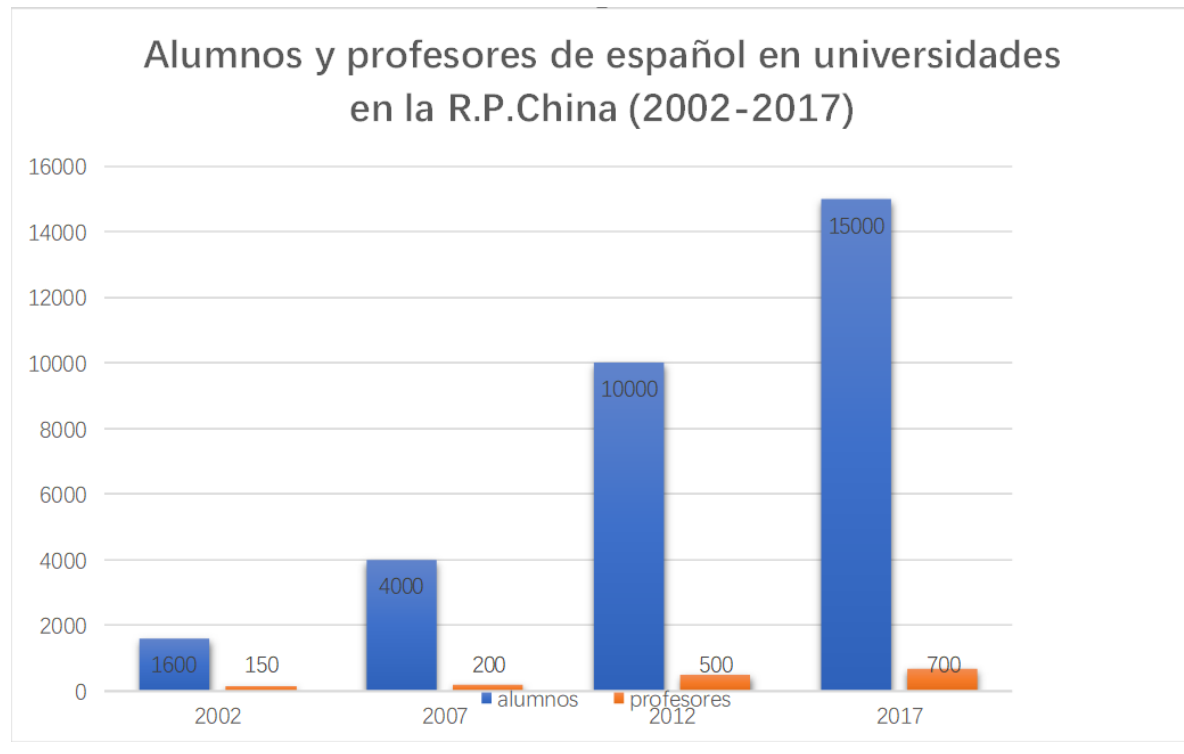

Como se puede observar, desde comienzos de siglo se viene observando un aumento exponencial de estudiantes de español en la R.P. China. No obstante, el número de profesores no crece al mismo ritmo.

A continuación vamos a dar cuenta de los diferentes contextos en los que se imparte la lengua de Cervantes en este país, con el propósito de presentar de manera lo más aproximada posible la envergadura que actualmente posee este campo en la tierra de Confucio.

\section{Contextos de enseñanza de ELE en la R.P. China}

Podemos encontrar diferentes contextos de enseñanza en los que se enseña español en la R.P. China. La enseñanza universitaria acapara el mayor porcentaje con un $50 \%$, como explicaremos más adelante, siendo este el contexto de enseñanza predominante. Este dato, por otro lado, también nos dice que aproximadamente un 50\% de los estudiantes de ELE se encuentran fuera del ámbito universitario, repartidos en diferentes ámbitos como la Enseñanza Secundaria o el Instituto Cervantes.

En el gráfico que presentamos a continuación podemos apreciar claramente los diversos tipos de contextos de enseñanza de ELE presentes en el ámbito sinohablante. 


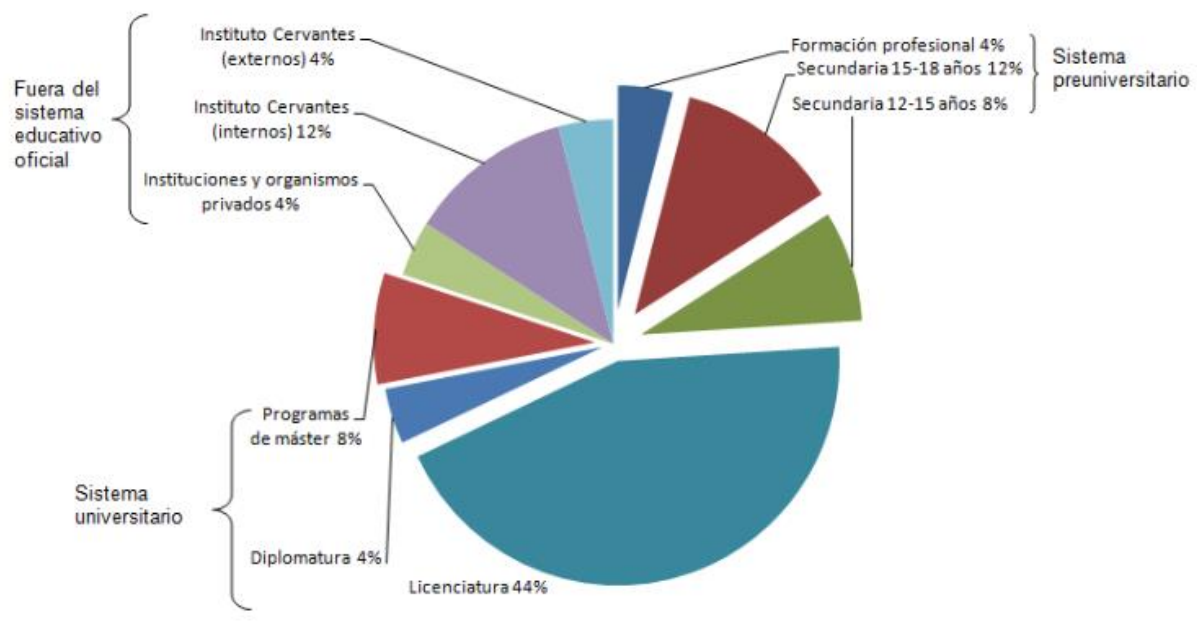

Fuente: Sánchez Griñán et al. (2011: 4)

Dentro del ámbito universitario encontramos principalmente tres niveles de estudios: el Grado en Filología Hispánica, estudios de diplomatura y estudios de posgrado (másteres). De acuerdo con la información presentada en el Simposio de enseñanza de español como especialidad en educación superior ${ }^{6}$, celebrado en la provincia de Heilongjiang en 2018, existen solamente tres universidades que imparten estudios de doctorado: la Universidad de Estudios Extranjeros de Pekín, la Universidad de Estudios Internacionales de Shanghái y la Universidad de Pekín.

Siguiendo con el análisis del gráfico, en él podemos apreciar que el resto de contextos se distribuye casi equitativamente entre la enseñanza no reglada y la enseñanza reglada. En los siguientes epígrafes vamos a analizar estos dos contextos.

\subsection{Enseñanza no reglada}

Tal y como nos muestra el gráfico de Sánchez Griñán et al. (2011), la presencia del español en el contexto de la enseñanza no reglada representa el 20\%, correspondiendo la gran mayoría, un 16\%, al Instituto Cervantes, lo que refleja la importancia con la que cuenta actualmente este organismo en la R.P. China. El Instituto Cervantes comenzó su andadura en la R.P. China en 2006, con la apertura del Instituto Cervantes de Pekín y continuó un año más tarde con la inauguración de otra sede en Shanghái. Por lo que respecta a otros centros privados de enseñanza no reglada, existe un incontable número. Uno de los que goza de más fama en China es la International House, con sede en Pekín, Xi'an y Qingdao. El profesor Alejandro Burgos, actualmente profesor de la Qianyi International School de Pekín (centro privado de enseñanza no reglada), nos habló con detalle acerca del funcionamiento de esta institución donde se organizan cursos intensivos, de 500 horas de duración, para universitarios que posteriormente recalan en algunas universidades españolas y latinoamericanas. Otra escuela muy

${ }^{6}$ La traducción es nuestra y está sacada del siguiente artículo: 全国高校西班牙语专业教学研讨会. 
conocida en China es XinDongFang (XDF), que tiene sucursales en muchas ciudades del país. Según el testimonio de la profesora Zhang Fan, responsable del departamento de español en la actualidad, la mayoría de estudiantes son universitarios que tienen intención de seguir formándose en España o en Latinoamérica, así como un grupo de adultos cuyos destinos laborales se sitúan en algún país de habla hispana.

Otro organismo con protagonismo en China es el Colegio Internacional: centro de enseñanza reglada por un currículum no chino. El currículum en estos casos es británico, americano, francés, alemán, etc. Por lo tanto, encontramos la enseñanza de ELE en el programa de la asignatura de segunda lengua o de lengua optativa en base al currículum educativo que corresponda.

En definitiva, existen numerosos centros que ofertan ELE y no solo a alumnos sinohablantes, sino también a alumnos extranjeros de las escuelas internacionales cuyo porcentaje supone alrededor de un $20 \%$.

\subsection{Enseñanza reglada}

Dentro de la enseñanza reglada podemos hacer una división en dos categorías: la preuniversitaria, en la que incluimos la enseñanza primaria, la secundaria y la formación profesional, y la universitaria, que comienza con el grado universitario y abarcaría hasta los estudios de doctorado.

\subsubsection{Enseñanza reglada preuniversitaria}

El Ministerio de Educación de España ofrece datos detallados sobre los centros de enseñanza primaria, secundaria y formación profesional. Según el documento publicado en su página web ${ }^{7}$, existen 57 centros oficialmente registrados en todo el país. No obstante, este número fluctúa constantemente.

Respecto del tipo de enseñanza que encontramos en estos centros, la asignatura de lengua española está encuadrada dentro del programa educativo escolar chino. El número de horas lectivas viene determinado por la modalidad de estudio, es decir, dependiendo de la opción que elijan los alumnos: como asignatura optativa o como segunda lengua.

Por otra parte, la Consejería de Educación de España tiene registradas cuatro Secciones Bilingües en todo el país ${ }^{8}$. Estas se encuentran en el Colegio de Lenguas Extranjeras de Pekín, en la Escuela de Lenguas Extranjeras de Ganguang de Shanghái, en la Escuela de Lenguas Extranjeras de Xi'an y en el Colegio de Lenguas Extranjeras de Jinan. Las Secciones Bilingües constituyen una iniciativa orientada a promocionar la lengua y la cultura en otros países, concretamente en centros públicos de Enseñanza Secundaria.

\footnotetext{
7 http://www.educacionyfp.gob.es/china/dam/jcr:cbd2c4dc-dce0-41ad-9769-15514b10625b/ii--centros-deeducaci-n-primaria-y-secundaria-2014-15-oct.pdf

8 Podemos encontrar la información en el siguiente enlace:

http://www.educacionyfp.gob.es/china/estudiar/en-china/china-centros-docentes.html
} 


\subsubsection{Enseñanza reglada de estudios universitarios}

Según datos oficiales publicados, en 2018 existían 91 departamentos de español con Grado en Filología Hispánica y 270 estudiantes de máster. El número de programas de máster va en aumento, aunque de un modo menos intenso que el de los grados. Por ejemplo, en 2012 había 12 programas de máster y en 2017 pasaron a ser 18 (Lu, 2018: 408-409) ${ }^{9}$.

La situación del español en las universidades chinas se mantiene en constante crecimiento, tanto en el caso del grado como en el de los programas de máster. No obstante, el doctorado en lengua española en la R.P. China sigue estando al alcance de un número muy reducido de estudiantes, obligando así a muchos estudiantes a realizar su doctorado en algún país de habla hispana.

\section{El Grado en Filología Hispánica en las universidades de la R. P.}

\section{China y sus particularidades}

Los primeros diseños curriculares referidos a la enseñanza de español en la R.P. China son el Programa de Enseñanza para Cursos Básicos de las Especialidades de Lengua Española en Escuelas Superiores Chinas (PCB) y el Programa de Enseñanza para Cursos Superiores de las Especialidades de Lengua Española en Escuelas Superiores Chinas (PCS) y vieron la luz en los años 1998 y 2000 respectivamente, ambos en la Shanghai Foreign Language Education Press. Su elaboración estuvo a cargo de la sección de español del Consejo Nacional de Orientación para la Enseñanza Universitaria de Lenguas Extranjeras (CNE), coordinado por el profesor Lu Jingsheng, actual decano de la prestigiosa Universidad de Lenguas Extranjeras de Shanghái (SISU). Estos dos programas, analizados detalladamente por el profesor Álvarez en su tesis doctoral (2012: 184), conforman las líneas maestras que siguen las universidades de la R.P. China. Asimismo, a pesar de los esfuerzos por unificar criterios para todas las universidades de la China continental, el Consejo Nacional ha pedido a todos los departamentos que cada universidad tenga su propia identidad. No obstante, existen ciertas directrices generales comunes a todos los departamentos, sobre todo aquellas encaminadas a tratar la conducta moral del alumnado. La máxima tradicional jiao shu yu ren (教书育人), mencionada por Sánchez Griñán (2008: 95), que se traduce como impartir conocimientos de los libros y educación moral a las personas, es una premisa que se encuentra presente no solo en los departamentos de español, sino en todas las carreras universitarias.

Sánchez Griñán (2008: 107) establece un análisis exhaustivo del PCB y del PCS, suficientemente esclarecedor como para conocer el panorama de la enseñanza de español en las universidades de la R.P. China. Además de exponer esta dicotomía enseñanza formal - enseñanza moral, también encontramos en su estudio una comparación entre estos diseños curriculares y los esquemas que ofrecen el Marco

\footnotetext{
${ }^{9}$ Según el profesor Lu, en una entrevista que tuvimos la oportunidad de realizarle en junio de 2020, seis nuevas universidades han obtenido el permiso para ofrecer el Grado en Filología Hispánica, así pues, son ya un centenar de departamentos de español los que ofrecen estos estudios en la R. P. China.
} 
Común Europeo de Referencia (MCER) y el Plan Curricular del Instituto Cervantes (PCIC), que podría resumirse en los siguientes puntos:

- En el programa chino encontramos una ausencia general de consideraciones pedagógicas y metodológicas; se omiten nociones como competencia comunicativa o pragmática, venidas de Occidente.

- La experiencia del profesor adquiere un gran valor, propiciando así que se produzca un estancamiento de creencias, actitudes y métodos, al no haber, por otro lado, reciclaje de conocimientos por parte del profesorado.

- Los planes de los estudios de español siguen un esquema rígido.

- Las nociones gramaticales y su grado de complejidad establecen la secuenciación de las clases. La competencia comunicativa queda al servicio de la interiorización de la gramática, con la creencia de que su desarrollo será consecuencia natural del estudio de las reglas gramaticales.

- No hay alusión a los contenidos culturales.

- No se menciona el papel de los profesores nativos en este tipo de enseñanza.

Consideramos oportuno exponer en este momento un resumen de los aspectos más destacados tanto del PCB como del PCS sobre su particular modo de ver la enseñanza de español. Tenemos que advertir que en estos programas se habla de contenidos específicos, pero también de los roles del profesorado y del alumnado. Por lo que respecta al programa para cursos básicos, los principios vienen divididos en 7 categorías:

- Carrera e ideología. El objetivo es formar a gente especializada en la lengua española y desarrollada integralmente en conceptos morales.

- Enseñanza y estudio. En cuanto al papel del profesor, se repite la dicotomía especialidad - moral; en cuanto al alumno, se persigue tanto el entusiasmo como el respeto al profesor y a los mayores en general. Asimismo, se menciona el objetivo de reforzar la conciencia de competición.

- Dominio lingüístico y arte comunicativo. Se menciona la fonética, el léxico, la gramática, así como las cuatro destrezas. En cuanto a la comunicación, como explicamos anteriormente, queda supeditada a estos saberes. Por otro lado, se explica que lo mejor es comparar lo chino y lo extranjero para fomentar el interés de los alumnos.

- Coordinar justamente las relaciones entre audición, habla, lectura y redacción. Se trabajan las cuatro destrezas por separado y se anima a la utilización de grandes cantidades de material lingüístico para garantizar una fuente caudalosa de expresión.

- Coordinar el estudio dentro y fuera de la clase. En este punto se apuesta por la utilización de nuevas tecnologías que puedan proveer a los alumnos de situaciones comunicativas lo más cercanas a su realidad. También se fomenta la organización de actividades fuera del aula, como conferencias, discursos o narraciones. 
Relacionar la lengua materna con el español. Se apuesta por no dejar el chino de lado y utilizarlo para hacer comparaciones cuando sea necesario.

En cuanto al programa para cursos superiores, encontramos un marcado carácter patriótico. La primera pauta comienza exponiendo que hay que poner en práctica las orientaciones y políticas educativas del Partido Comunista para formar así personal especializado para la construcción moderna del socialismo en China, cumpliéndose así la premisa principal que plantean las continuas reformas educativas en la R.P. China: la creación de talentos avanzados y expertos para la construcción de la modernización socialista. El texto continúa dando importancia tanto a la formación de especialidad como a la moral, y a la inculcación del patriotismo y el colectivismo en los alumnos. Respecto a la competencia comunicativa, se le sigue dando importancia al arte comunicativo, pero no se establece ninguna pauta metodológica. Más adelante en este documento se vuelve a poner el foco en la nación, recalcando la importancia de los profesionales de la lengua en la nueva economía de mercado. Podemos concluir que uno de los objetivos principales es el de dar esplendor a la civilización china, aportando profesionales especializados a la sociedad.

Conceptos como la moral, el respeto al profesor y los mayores y la conciencia de la existente competencia nos hacen ver que nos enfrentamos a una manera de concebir la educación un tanto alejada de los parámetros occidentales. En nuestra experiencia impartiendo clase en universidades de la R.P. China hemos podido observar que los parámetros sobre los que se cimienta la educación universitaria dan a lugar a una serie de características exclusivas y claramente apreciables en el aula ${ }^{10}$. A continuación vamos a enumerar aquellas que, contienen una diferencia sustancial con nuestra propia cultura:

- Respeto a la figura del profesor. El profesor dispone en el aula bajo la atenta mirada de los estudiantes, que excepcionalmente discuten el contenido o la forma de proceder en clase. Este hecho no quiere decir que los estudiantes acepten de buen grado la disposición del profesor, sino que no lo expresan públicamente, ya que culturalmente no está bien visto por el resto de los compañeros. Un hecho similar ocurre a la hora de plantear dudas en público; un número muy reducido de ellos se atreven a preguntar alguna duda en clase debido a dos razones principalmente: la primera es por vergüenza o temor a hablar en público (hecho muy extendido entre los estudiantes universitarios) y la segunda es la preocupación por dejar en entredicho al profesor.

- Notable importancia del manual. El libro de texto utilizado en clase resulta de gran importancia para los alumnos. El manual por excelencia para la enseñanza de la gramática y del vocabulario es el manual Español Moderno. Los contenidos que presenta difícilmente se discuten; su autor, Dong Yansheng, considerado una auténtica eminencia en China, es muy respetado por todos los profesores chinos de

10 Estas características son difícilmente cuantificables y únicamente apreciables por un profesor extranjero ajeno a esta cultura, al poder compararlo con su propia cultura. 
español y por los estudiantes por ser uno de los pioneros en dedicarse a la docencia y estudio del español en la R.P. China.

- Repetición y memorización. Este punto está relacionado con la creencia de que con la repetición y la memorización se aprende de manera adecuada, ya que la metodología que predomina en él es, principalmente, el método estructuralista, donde la repetición y la memorización de estructuras gramaticales resulta clave en el proceso de enseñanza - aprendizaje. Esto, para el profesor nativo de español, puede producir cierto choque, ya que, a la hora de poner en práctica la competencia comunicativa, verá cómo los estudiantes suelen repetir las mismas estructuras una y otra vez, dando poco lugar a la improvisación o a la creatividad.

- Combinación entre asignaturas relacionadas con el español y asignaturas de corte político. Es común ver que, después de nuestra clase, los estudiantes pueden tener asignaturas relacionadas con el marxismo o con la teoría política del Partido Comunista; el tiempo del Grado en Filología Hispánica es compartido por las asignaturas relacionadas con la lengua española y por otro tipo de asignaturas muy alejadas del aprendizaje del español.

A continuación, profundizaremos en los planes de estudio del Grado en Filología Hispánica, con el fin de comentar las distintas asignaturas que se imparten y señalar las diferencias más significativas.

\subsection{Los planes de estudio del Grado en Filología Hispánica en las universidades de la R. P. China}

Siguiendo las pautas que aparecen en el documento titulado Estándar Nacional de Calidad de Enseñanza para la Licenciatura Universitaria de Español, en 2014 la sección de español del Consejo Nacional de Español de la R.P. China trató de aunar los criterios para el Grado en Filología Hispánica ofrecido en las universidades de toda la China continental. Este documento de momento es solo un borrador, ya que se encuentra en constante revisión, pero es un documento que poseen todos los departamentos de español de la R.P. China. En el segundo capítulo se menciona una duración de cuatro años para el grado, estructura que se aplica en todas las universidades que ofrecen el Grado en Filología Hispánica.

Los Requerimientos de Conocimiento se basan en tres pilares: lengua, literatura y cultura. En el primero, se explica que los estudiantes deben dominar la pronunciación, el vocabulario, la gramática, el discurso, la retórica, etc. También se mencionan conocimientos como las expresiones idiomáticas y el uso de la lengua en las diferentes regiones. En el segundo, se dice que los alumnos deberán conocer la historia de la literatura de los países de habla hispana, los principales géneros literarios y los escritores más importantes, así como sus obras. En lo que respecta a la cultura, se expone que los estudiantes deberán aprender la historia de los países hispanohablantes, así como la política, la economía y su cultura. Por otra parte, también se habla de establecer una comparación de las características básicas de la cultura china y la cultura occidental. 
Las asignaturas establecidas se dividen en públicas, profesionales nucleares y asignaturas de orientación profesional, además de prácticas y una tesina de obligatoria elaboración. Estas asignaturas conformarían un grado de, generalmente, 160 - 180 créditos (ECTS), con un total de 2600 - 2900 horas. Las asignaturas públicas, denominadas así porque son comunes a todos los grados, incluyen Teoría Política, Tecnología y Educación Física, además del entrenamiento militar al inicio del grado y el estudio de una segunda lengua. Las asignaturas profesionales nucleares se dividen en habilidades y cursos de especialidad; las habilidades pretenden desarrollar cuatro destrezas básicas: escuchar, hablar, leer y escribir, además de traducción e interpretación, e incluyen asignaturas como Español Hablado, Comprensión Auditiva, Lectura Intensiva o Teoría y Práctica de la Traducción; entre las asignaturas de especialidad se encuentran Literatura, Cultura, Gramática Española, Redacción de Tesis o Investigación Básica. Las asignaturas de orientación profesional pueden incluir conocimientos incluidos en otro grupo de asignaturas, como Literatura o Traducción, o asignaturas como Español Audiovisual o Interculturalidad, más específicas de este grupo. Para estas asignaturas en el Estándar Nacional se explica que las universidades pueden ajustar de manera independiente la distribución de las asignaturas de formación profesional en función de sus propios objetivos.

A continuación vamos a presentar información de diversa índole sobre el Estándar Nacional que cabe destacar. En primer lugar, no encontramos en este documento alusión a la competencia comunicativa; podemos leer únicamente que se debe hacer un uso eficaz de las estrategias para mejorar la eficacia de la comunicación, pero no se profundiza en este tema. En segundo lugar, se hace mención a que los departamentos deben estar formados por líderes académicos y profesores extranjeros. El concepto de líder académico se refiere a profesionales de la lengua que por su carrera y currículo son ubicados en un alto lugar en el escalafón de profesores chinos de español.

Con respecto al elemento cultural, en este documento podemos leer que el alumno debe ser capaz de analizar las diferencias culturales y cumplir con el trabajo de comunicación intercultural. Por tanto, no es de extrañar que la asignatura de Interculturalidad sea considerada asignatura de especialidad en el Grado en Filología Hispánica ${ }^{11}$. En resumen, y como hemos anunciado anteriormente al hablar de las peculiaridades del Grado en Filología Hispánica en China, las horas lectivas se completan con asignaturas relacionadas con la Filología Hispánica y con asignaturas alejadas de ella; la formación específica debe ser completada siempre, según los planes de estudios universitarios en la R.P. China, con asignaturas relacionadas con teoría política, marxismo, educación física e incluso dos semanas de formación militar, que tienen como objetivo fomentar tanto el compañerismo como la obediencia.

11 Para un mayor conocimiento de los planes de estudio, en Álvarez (2012: 550) y en Vázquez Torronteras (2019: 393), podemos encontrar información detallada sobre los planes de estudio del Grado en Filología Hispánica en varias universidades chinas. 


\section{Conclusiones}

El español en la R.P. China tuvo su momento de eclosión en los años ochenta y, actualmente, está viviendo su apogeo. El número de estudiantes que en la actualidad dedica parte de sus esfuerzos a aprender español es especialmente relevante en las universidades. Como ya hemos expuesto, todos los años hay universidades que implantan el Grado en Filología Hispánica en sus aulas. Al mismo tiempo, los contextos de enseñanza se diversifican a medida que pasan los años; cada vez es más habitual encontrarnos con la enseñanza de español en la enseñanza secundaria e incluso, aunque todavía de una forma excepcional, en primaria.

A lo largo de este artículo hemos expuesto los datos y la información que, en la actualidad, aparecen recogidos en los documentos oficiales. Nuestras fuentes de información han sido estos escritos, nuestras propias observaciones de clase y también diferentes entrevistas realizadas a personalidades y profesionales de la enseñanza de español en la R.P. China. Esta combinación de recursos nos ha permitido elaborar un mapa, lo más real posible, de la situación que se vive en la actualidad en la China continental en lo que a la enseñanza de español se refiere.

Nos hemos centrado particularmente en la enseñanza de español en el grado universitario. Respecto de este contexto hemos podido observar las particularidades propias de un país como la R.P. China, donde la enseñanza de las diferentes destrezas que configuran la enseñanza del español comparte horas lectivas con asignaturas de corte y contenidos muy diferentes, como las relacionadas con la teoría política, el marxismo o la educación física. Esta combinación de asignaturas (muy diferente a los planes de estudios de filología a los que estamos habituados en Europa) aparentemente no interfiere en el progreso del nivel de español de nuestros estudiantes, que es en definitiva nuestra labor. No obstante, debemos constatar que la política tiene una gran influencia en la sociedad china por lo que no es de extrañar que los planes de estudios universitarios, independientemente de la materia que traten, contengan asignaturas como las ya mencionadas .

Es indudable que el estudio de español, que comenzó en el S.XVI con la llegada de los primeros misioneros evangelizadores, está de moda en el S.XXI y se está extendiendo por todos los niveles educativos y en diferentes contextos. Teniendo en cuenta el número de habitantes en edad de estudiar en China y, a la vista de lo que ya ha sucedido, en los próximos años asistiremos, sin ningún lugar a duda, a una expansión todavía mayor del estudio de la lengua de Cervantes en China.

\section{Referencias bibliográficas}

ÁLVAREZ, A. (2012). El tratamiento de la interculturalidad en el aula con alumnos sinohablantes. Tesis doctoral. Granada: Universidad de Granada.

DONG, Y. (2009). Elaboración de materiales didácticos en China. Actas I Congreso de Español como Lengua Extranjera en Asia - Pacífico.

[https://cvc.cervantes.es/ensenanza/biblioteca_ele/publicaciones_centros/pdf/ manila_2009/06_plenaria_03.pdf] [última consulta: 7 de julio de 2020] 
FISAC, T. (2000). La enseñanza del español en Asia Oriental. El español por el mundo. Anuario del Instituto Cervantes 2000, 229-298.

[http://cvc.cervantes.es/lengua/anuario/anuario_00/fisac/p02.htm] [última consulta: 7 de julio de 2020]

GIL, J. (2019). El dictionarivm Hispano-Sinicvm de la Universidad de Santo Tomás (Manila). Fundación Ramón Menéndez Pidal.

[http://www.fundacionramonmenendezpidal.org/portfolio/el-dictionarivmhispano-sinicvm-de-la-universidad-de-santo-tomas-manila-por-juan-gil/] [última consulta: 7 de julio de 2020]

GONZÁLEZ PUY, I. (2006). El español en China. El español en el mundo. Anuario del Instituto Cervantes 2006-2007: 133-142.

[http://cvc.cervantes.es/lengua/anuario/anuario_06-07/pdf/paises_24.pdf]

[última consulta: 7 de julio de 2020]

HUANG, W. (2014). La enseñanza del español en China. V Congreso Internacional de FIAPE: ¿Qué español enseñar y cómo? Variedades del español y su enseñanza. [http://www.mecd.gob.es/dctm/redele/Material-

RedEle/Numeros\%20Especiales/2015-v-congreso-fiape/comunicaciones/15.-

laensenanza-del-espanol-en-china--

huangwei.pdf?documentId=0901e72b81ec605c] [última consulta: 7 de julio de 2020]

LIN, L. (2015). Andanzas de Don Quijote y ELE en China. Actas del VIII Congreso Internacional de la Asociación Asiática de Hispanistas, Shanghái Foreign Language Education Press, 422-431.

LU, J. (2018). 助力西班牙语教学的快速发展, 往事历历 40 年回眸 : 知名外语学者与改 革开放. 上海外语教育出版社.

LU, J. (2014). La génesis y el desarrollo de los estudios de español en China. El español en el mundo. Anuario del Instituto Cervantes.

[http://cvc.cervantes.es/lengua/anuario/anuario_14/jingsheng/p01.htm]

[última consulta: 7 de julio de 2020]

MARCO, C. y MARCO, J. (2010). La enseñanza del español en China: evolución histórica, realidad actual y perspectivas. Revista Cálamo FASPE, ISSN-n: 1136-9493, n. ${ }^{\circ 56}$, octubre - diciembre 2010, 3-14.

[http://dialnet.unirioja.es/descarga/articulo/3402357.pdf] [última consulta: 7 de julio de 2020]

SÁNCHEZ GRIÑÁN, A. (2008). Enseñanza y aprendizaje de español como lengua extranjera en China. Retos y posibilidades del enfoque comunicativo. Tesis doctoral, Murcia, España.

SÁNCHEZ GRIÑÁN, A., BLANCO PENA, J., ARRIAGA, N., CHEN ZHI, L., DEZA, P., VÁZQUEZ VÁZQUEZ, M. (2011). Contextos de enseñanza y aprendizaje de ELE en el ámbito sinohablante. Monógraficos SinoELE, enero-junio 2011, ISSN: 20765533. [http://www.sinoele.org/images/Proyectos/Contextos/memoria.pdf] [última consulta: 7 de julio de 2020] 
SANTOS ROVIRA, J. 2011. La enseñanza del español en China: historia, desarrollo y situación actual. ISBN: 9788492658169. Lugo: Axac.

VÁZQUEZ TORRONTERAS, A. (2019). Contraste cultural en la enseñanza de español con alumnos sinohablantes en la R.P. China. Tesis doctoral, Jaén: Universidad de Jaén.

ZHANK, K. (2009). 庞迪我与中国， 大象出版社. Traducción en español: LUO, H. (2018). Diego de Pantoja y China, Editorial Popular.

ZHENG, S. y LIU, Y. (2011). La investigación del profesorado en la especialidad de lengua española en la enseñanza superior de China. Foreign Language Teaching and Research, julio de 2014, Vol. 46, n.누 596-604.

ZHENG, S., Liu, Y., Wang, M. (2011). La investigación de las asignaturas de la Licenciatura en la especialidad de lengua española en la enseñanza superior de China. Foreign Language Teaching and Research, julio de 2011, Vol. 43, n.ํ4, 574-582. 